\title{
Suppression of Thermal Crown of Heating Roll for Large Area Thermal Imprint with Consideration of Thermal Resistance between Roll and Shaft
}

\author{
Byeong-Jun Moon', JongHyun Kim', and Sun-Kyu Lee ${ }^{1, \#}$ \\ 1 School of Mechatronics, Gwangju Institute Science and Technology, 123, Cheomdangwagi-ro, Buk-gu, Gwangju, 61005, South Korea \\ \# Corresponding Author / E-mail: skyee@gist.ac.kr, TEL: +82-62-715-2388, FAX: +82-62-715-2384
}

KEYWORDS: Roll to roll, Thermal imprint, Heating roll, Thermo-Mechanical design, Thermal contact

\begin{abstract}
Printed electronic circuits are becoming increasingly employed in flexible electronics such as radiofrequency (RF) antenna modules and organic solar cells. To achieve a high-efficiency module, very thin and small electrodes need to be produced with high throughput. This work reports on a heating roll design for the roll-to-roll $(R 2 R)$ thermal imprinting process. Due to non-uniform thermal deformation of the roll, it is difficult to produce uniform electrodes throughout the large surface. This investigation focused on a thermo-mechanical design for the heating roll that improves the uniformity of its temperature and thermal deformation. This paper presents the design procedure and fabrication process of the R2R thermal imprinting. Applying this method for optimizing the heating roll will contribute to large area imprinting and high uniformity.
\end{abstract}

Manuscript received: February 11, 2015 / Revised: June 29, 2015 / Accepted: July 6, 2015

\section{Introduction}

Recently, printed electronics products have become increasingly employed in flexible electronics, such as radiofrequency (RF) antenna modules and organic solar cells. Many researchers have carried out various works to improve and develop manufacturing devices and methods related to the printed electronics as follows. For example, Chou et al. (1996) proposed nanoimprint lithography for fabrication of nanoscale photo detectors, silicon quantum dots, quantum wires, and ring transistors at high throughput and low cost. ${ }^{1}$ Yu et al. (2012) fabricated silver front electrode grids for indium tin oxide (ITO)-free printed organic solar cells using the flexographic and inkjet roll-to-roll (R2R) thermal imprint process. ${ }^{2}$ Lee et al. (2013) performed an FEM analysis of the stress level during the screen printing process. ${ }^{3}$ This analysis considered the effects of the squeegee pressure, angle, and snap-off on the stress distribution in the fabrication of a crystalline silicon solar cell with lower breakage rate. Jeong et al. (2014) designed an air flotation oven as a dryer in R2R and analyze a drying process. ${ }^{4}$ The air flotation oven is commonly used for the noncontact support and drying of coated web materials such as plastic films and paper. Kim et al. (2014) presented plate-to-roll transfer of nanoscale thin films using an elastomer-covered roll with buffer cavities to suppress defects such as cracks and wrinkles in the transferred film. ${ }^{5}$ Kang et al. (2014) derived a mathematical modeling of the register for the hybrid printing systems, which consisted of contact printing and non-contact printing such as gravure and inkjet printing. ${ }^{6}$

To achieve a high-efficiency module, very thin and small electrodes need to be produced with high throughput. Imprint lithography has attracted attention for its ability to overcome the disadvantages of photo lithography, such as the difficulty of mass production at low cost and over a large area exposure. Haisma et al. (1996) proposed moldassisted nanolithography, which uses a UV-curable polymer. ${ }^{7}$ Bender et al. (2000) fabricated nanostructures using UV imprint lithography with low pressure and room temperature printing and easy detachment of the mold. ${ }^{8}$ Ahn et al. (2006) fabricated a continuous ultraviolet roll nanoimprint lithography system which achieved thickness uniformity while replicating large-scale nano- and micro-sized patterns. ${ }^{9}$

The other is a thermal imprint lithography method which thermal imprint lithography uses the glass transition temperature to improve replication efficiency, because the Young's modulus of the polymer dramatically decreases near the glass transition region. Due to this merit, thermal imprint lithography has been widely applied to the fabrication of large area $\mathrm{R} 2 \mathrm{R}$ or roll-to-plate (R2P) processes, which produce a high throughput in a continuous process with uniform 
quality. Yeo et al. (2009) microfabricated a polymeric device using hot roller embossing that accounted for process parameters such as the embossing pressure, substrate preheating, roller temperature, ${ }^{10}$ and roller speed. Lan et al. (2010) performed a continuous roll-to-flat thermal imprinting process for large-area micro-pattern replication on polymer substrates and investigated a cavity-filling mechanism based on the Hertz contact pressure distribution and Navier-Stokes equation. ${ }^{11}$ Kettle et al. (2013) performed thermal imprint lithography for flexible, low-bandgap organic solar cells. ${ }^{12}$ The process is compatible with PET substrates with the use of an intermediate low glass transition temperature polymer.

The pattern replication process in imprint lithography is performed by physical contact. The heating roll is adopted for both heating and pressing on the film in the R2R thermal imprinting system. However, it is very difficult to achieve a uniform pressure along the axial direction due to the non-uniform thermal deformation and temperature distribution of the heating roll. The steel industry is also interested in reducing the thermal deformation of the roll, which is called the thermal crown because it affects the strip's flatness and productivity. Tsengal et al. (1997) performed a parametric study to provide needed information regarding proper control of the roll and strip shape during the operation of a high-speed rolling mill. ${ }^{13}$ An understanding of the thermal expansion of the roll is essential for proper control of its flatness.

Guo et al. (2006) performed a transient FEM analysis of the temperature field and thermal crown of the roll during hot rolling for improvement of the strip profile. ${ }^{14}$ Abbraspour and Saboonchi (2008) developed a finite difference model under transient conditions to calculate the temperature and thermal crown profile in the roll. ${ }^{15}$ This method is able to accept a variable boundary condition in the circumferential and axial directions for different cooling configurations.

The temperature distribution affects the Young's modulus of the film, while the thermal deformation profile of the heating roll influences the printed pattern's thickness and line width over the entire area. These factors directly cause a lack of uniformity of the printed patterns. For this reason, the present work considered the thermal deformations as well as the temperature distribution of the heating roll as the key issues for achieving a large area pattern with high uniformity.

In this study, the new design method was proposed to minimize the thermal deformation of heating roll in the thermal imprint system. In general, the heating roll has been manufactured by cylindrical one solid body (left in Fig. 1), in which heaters are inserted peripherally. Newly designed roll is manufactured by separating cylindrical roll and shaft, and then assembled with press-fitting (right in Fig. 1). The press-fit contact widths between cylinder and shaft are designed so that temperature distribution may be modified as depicted in Fig. 1. A thermal deformation of heating roll is also changed based on modified temperature distribution. R2R thermal imprinting was performed while consideration of the pressure, speed, temperature, and performance of the newly designed heating roll was evaluated.

\section{Design of Heating Roll}

Conventionally, heating rolls have been fabricated as a monolithic cylindrical structure using an induction heat method. Yun et al. (2012) developed the R2R hot embossing system with an induction heating

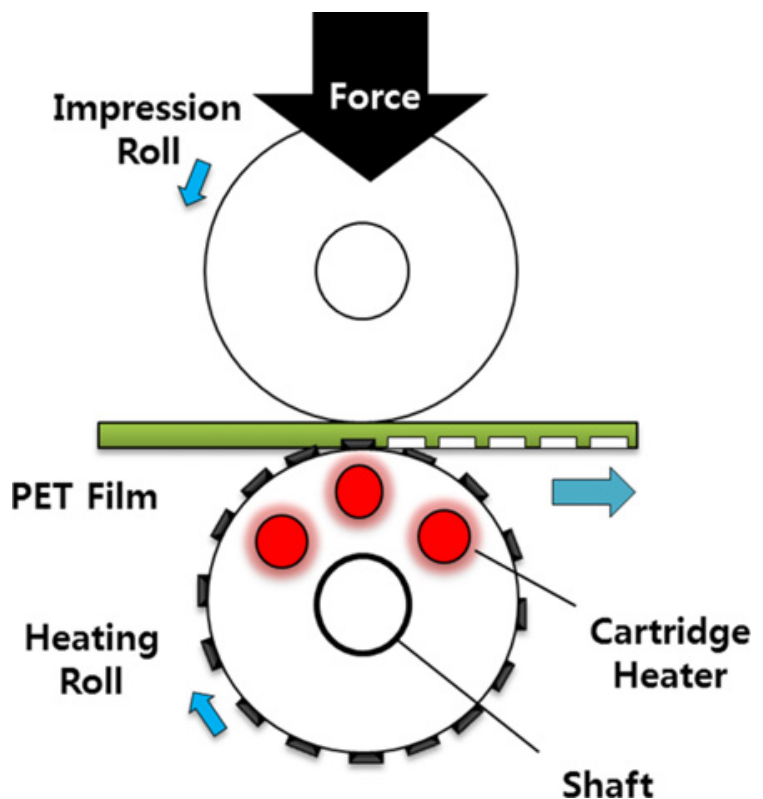

Fig. 2 Heating roll used in the thermal imprinting
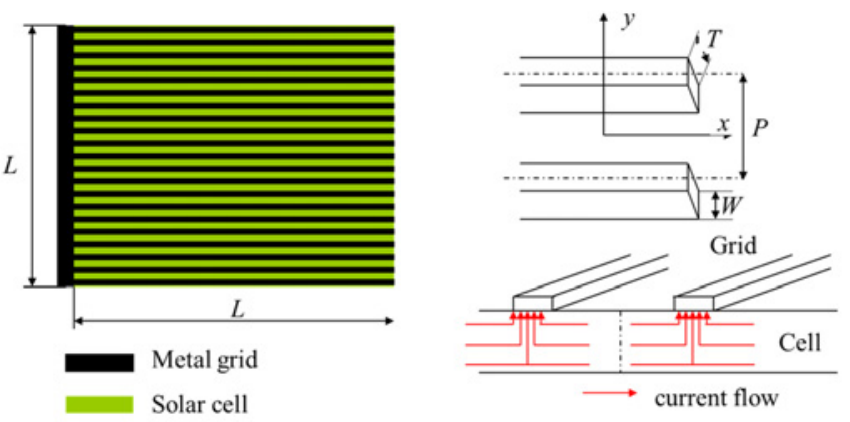

$$
\begin{array}{llll}
\text { Terms } & J_{M} \text { current density } & \rho_{M} \text { metal resistance } & P \text { period of grid } \\
& V_{M} \text { Open circuit voltage } & \rho_{C} \text { contact resistance } & L \text { Area } \\
& \rho_{S} \text { sheet resistance } & T \text { thickness of grid } & W \text { width of grid }
\end{array}
$$

Fig. 3 The schematic view of the grid design

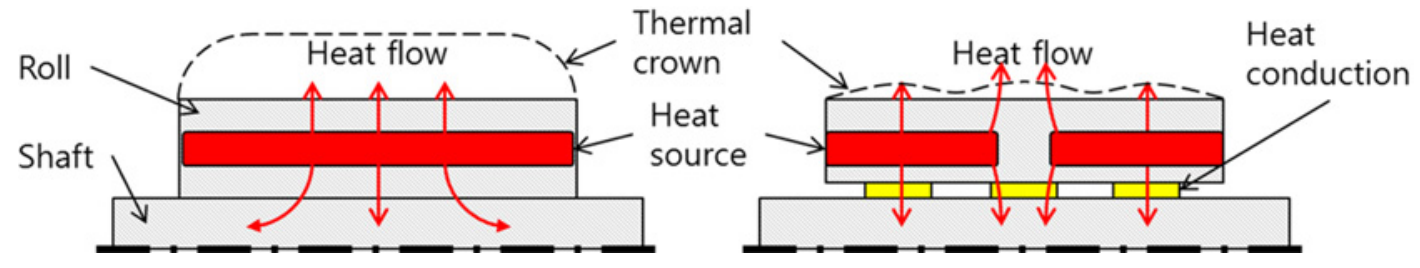

Fig. 1 Schematic view of heat path design; (left) cylindrical one solid body model, (right) proposed model considering heat conduction between a shaft and roll 
method for micro-sized pattern fabrication. ${ }^{16}$ In this study, the heating roll cylinder and the shaft were separately fabricated and both were assembled with a press fit to improve the uniformity of temperature and thermal deformation. Sixteen cartridge heaters were inserted into the roll while several protrusions were fabricated on the shaft surface.

A replaceable imprint mold that has small patterns was attached on the surface of the heating roll. Ali Cheknane (2011), Mahmoud M. Shabana (1989) proposed the pattern dimension's optimization methods for ITO-free organic photovoltaic devices. ${ }^{17,18}$ The pattern was optimized using a genetic algorithm which considers the spreading resistance, line drop, contact resistance, and shadowing loss as shown in Figs. 3 and 4. Imprint mold was fabricated based on genetic algorithm results as shown in Table 1 .

Fig. 2 depicts a heating roll with the thermal imprint lithography, and Fig. 5 shows the heating roll and shaft assembled through protruding surface contacts. The assembled protruding surfaces provided heat paths from the heating roll into the shaft. By properly designing the location and area of the protruding surface, the temperature distribution and the thermal deformation can be improved. Through a thermo-mechanical analysis and design of experiment (D.O.E), the protruding surface was optimally designed in terms of spacing and width.

\section{Main loss}

$$
\begin{aligned}
& \longrightarrow \text { Spreading resistance in the surface sheet } \\
& \qquad F_{S R}=\frac{J_{M} \rho_{S}}{12 V_{M}} P^{2}, \quad F_{S R}=f\left(P^{2}\right) \\
& \longrightarrow \text { Line drop } \\
& \qquad F_{L D}=\frac{J_{M} \rho_{M}}{12 V_{M}} \frac{L^{2} P}{T W}, \quad F_{L D}=f\left(L^{2}, P, T, W\right) \\
& \longrightarrow \text { Constant resistance }
\end{aligned}
$$

$$
F_{C R}=\frac{J_{M} \rho_{C}}{V_{M}} \frac{W}{P}, \quad F_{C R}=f(W, P)
$$

Shadowing loss

$$
F_{S L}=\frac{W}{P}, \quad F_{S L}=f(W, P)
$$

Object function $F_{L O S S}=F_{S R}+F_{L D}+F_{C R}+F_{S L}$

Minimize with genetic algorithm (GA)

Optiminze parameter: [L, P, T, W]

Fig. 4 The formulation of the optimization process

Table 1 The results of optimal grid dimension

\begin{tabular}{ccccccccc}
\hline $\begin{array}{c}\text { Cell area } \\
{[\mathrm{mm}]}\end{array}$ & $\begin{array}{c}\mathrm{P} \\
{[\mathrm{mm}]}\end{array}$ & $\begin{array}{c}\mathrm{T} \\
{[\mathrm{mm}]}\end{array}$ & $\begin{array}{c}\mathrm{W} \\
{[\mathrm{mm}]}\end{array}$ & $\begin{array}{c}\mathrm{F}_{\mathrm{SR}} \\
{[\%]}\end{array}$ & $\begin{array}{c}\mathrm{F}_{\mathrm{LD}} \\
{[\%]}\end{array}$ & $\begin{array}{c}\mathrm{F}_{\mathrm{CR}} \\
{[\%]}\end{array}$ & $\begin{array}{c}\mathrm{F}_{\mathrm{SL}} \\
{[\%]}\end{array}$ & $\begin{array}{c}\text { Total } \\
\text { loss }\end{array}$ \\
\hline $200 \times 200$ & 0.47 & 0.02 & 0.02 & 0.08 & 4.2 & 0.01 & 0.04 & 4.33 \\
\hline
\end{tabular}

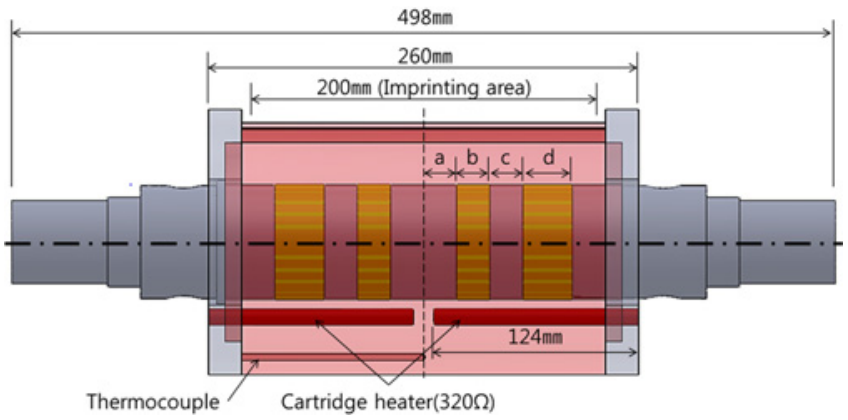

Fig. 5 Schematic view of the assembly of heating roll and shaft

\subsection{Shaft Configuration}

Both the initial profile and the thermal deformation of the heating roll had a significant influence on the pressure uniformity in the thermal imprinting process. The initial profiles of the heating roll, regrinding after shrinkage fit, were measured by the roundness measurement machine (Tokyo Precision Instrument, EC3200W) and indicated about $1.8 \mu \mathrm{m}$ of maximum radial variation along the axial direction, as shown in Fig. 6. In this study, the cylindrical body and the shaft of the heating roll were separately designed and were not monolithic, enabling the design of the heat path from the heating roll to the shaft. There were $25 \mu \mathrm{m}$ of protrusions fabricated on the shaft (diameter $70 \mathrm{~mm}$ ), and the shaft was assembled through a shrink fit onto the roll as depicted in Fig. 7. The contact pressure of the interface was calculated by Eq. (1) according to the geometric relation as shown in Fig. 7, which is taken from Shigley's Mechanical Engineering Design, $8^{\text {th }}$ edition. ${ }^{19}$

$$
\begin{gathered}
P=\frac{\delta}{\frac{d_{2}}{E_{2}}\left[\frac{d_{3}^{2}+d_{2}^{2}}{d_{3}^{2}-d_{2}^{2}}+v_{2}\right]+\frac{d_{2}}{E_{1}}\left[\frac{d_{2}^{2}+d_{1}^{2}}{d_{2}^{2}-d_{1}^{2}}+v_{1}\right]}[P a]=24.4 \mathrm{MPa} \\
d_{1}=15 \mathrm{~mm}, d_{2}=35 \mathrm{~mm}, d_{3}=80 \mathrm{~mm}, E_{1,2}=200 \mathrm{GPa}, \\
v_{1,2}=0.24, \delta=25 \mu \mathrm{m}
\end{gathered}
$$

\subsection{Thermo-Mechanical Analysis}

A thermo-mechanical analysis was conducted for the assembled heating roll. In the thermal analysis, the shaft and the cylindrical roll

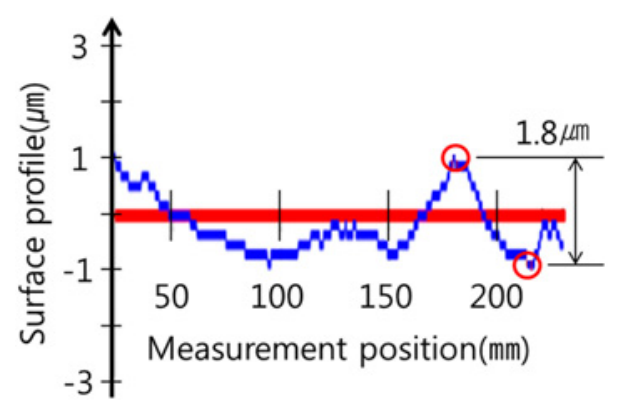

Fig. 6 Initial profile of the heating roll

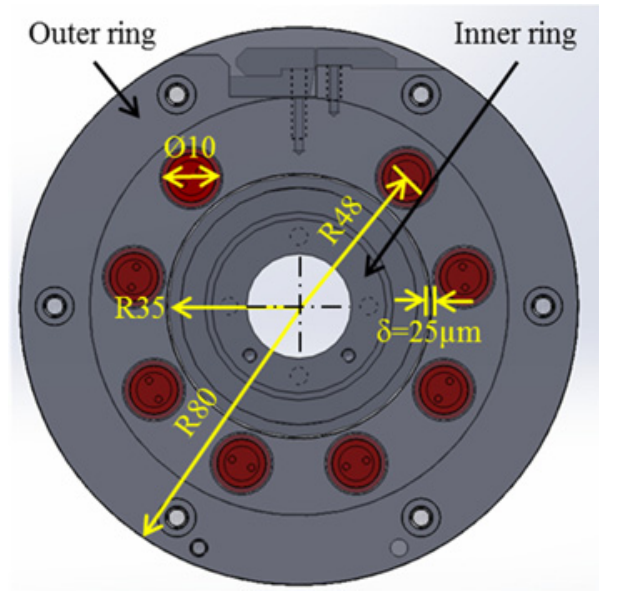

Fig. 7 The geometric relation of the shrinkage fit 
were treated as a single body, in which the two parts were connected at the protrusion. This assumption can be reasonable since the thermal contact resistance of the shrink fit with a smoothly finished surface can be neglected according to the reference. ${ }^{20-23}$ In addition, Iswor et al. (2013) performed experiment using house-made thermal interface tester using quite high pressure, in which thermal contact resistance doped with thermal interface material. ${ }^{24}$ The calculated contact pressure of the shrink fitted roller-shaft as single material but also can its variation be negligibly small when the contact pressure changes in a small amount. Therefore, for simplicity of calculation, the fitted contact zones are approximated as complete contact.

Moreover, it was assumed that there exists heat radiation between the roll and shaft surface at the non-contact portion zone. With the temperature distribution of the axisymmetric heating roll supplied by $120 \mathrm{~W}$ ( $7.5 \mathrm{~W}$ per heat cartridge), the thermal deformation of the roll was obtained using the COMSOL structural analysis software. In this structural analysis, the internal pressure corresponding to the shrink fit (i.e., 24.4 MPa) was applied. Fig. 8 shows an example of the temperature distribution of the assembled heating roll according to the simulation conditions represented in Table 2.

\subsection{Design of the Shaft}

In this work, the temperature distribution was intended to be designed via heat flow from the cylindrical body to the shaft, which eventually results in the suppression of the thermal crown of the heating roll along the axis. The thermal contact between the roll and shaft can be considered as a design issue; namely, the locations and the widths of the protrusions on the shaft surface can be selected properly. Fig. 9 shows a schematic of the design parameters, where a and c represent non-contacts, and $\mathrm{b}$ and $\mathrm{d}$ represent protrusions. D.O.E was employed to find the optimal dimensions of the contact and noncontact. The optimized values were effectively found through the orthogonal array and analysis of variance (ANOVA). In this process, a Plakett-Burman design was selected because it greatly reduced the number of experiments. It was designed with four control factors and

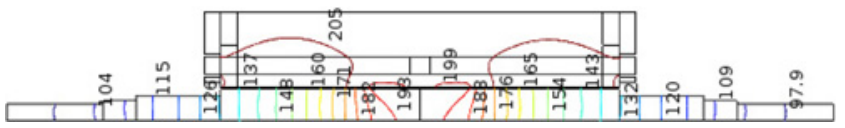

Fig. 8 Example of the temperature distribution of the heating roll using a numerical model

Table 2 Basic simulation conditions

\begin{tabular}{cc}
\hline Properties & Value \\
\hline Initial temperature & $20^{\circ} \mathrm{C}$ \\
\hline Ambient temperature & $20^{\circ} \mathrm{C}$ \\
\hline Heat input & $120 \mathrm{~W}$ \\
\hline Emissivity & 0.15 \\
\hline Convection coefficient & $10 \mathrm{~W} / \mathrm{m}^{2} \cdot \mathrm{K}$ \\
\hline
\end{tabular}

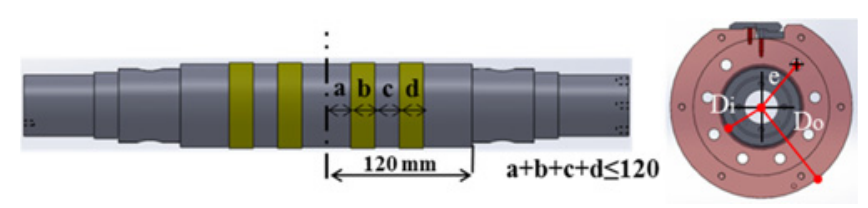

Fig. 9 Schematic of the design parameters two levels, and it was a 12th-order experiment. The initial serials of values were set in consideration of the initial constrained condition. The performance of each experiment in terms of temperature variation and thermal deformation of the heating roll was calculated using the commercial software COMSOL, as depicted in Fig. 8. In the D.O.E process, the summation of $\mathrm{a}, \mathrm{b}, \mathrm{c}$, and $\mathrm{d}$ was constrained to be less than $120 \mathrm{~mm}$. Table 3 indicates the initial constraints of each parameter in the D.O.E.

The analysis was repeatedly performed about the variation of the thermal deformation until it reached less than $5 \mu \mathrm{m}$ according to a flowchart in Fig. 10, as guided by the rule, 'the smaller the thermal deformation, the better the performance.'

Through the reset algorithm as shown in Fig 11, we trace the optimized new serial of values. Second orthogonal array's ANOVA results shows the over $90 \%$ R-square modify value of the reliability of optimization, the optimal parameters of $\mathrm{a}, \mathrm{b}, \mathrm{c}$, and $\mathrm{d}$ were obtained as $10 \mathrm{~mm}, 10 \mathrm{~mm}, 0 \mathrm{~mm}$, and $10 \mathrm{~mm}$, respectively, as indicated in Table 4 .

Table 3 Initial constraints of design parameters

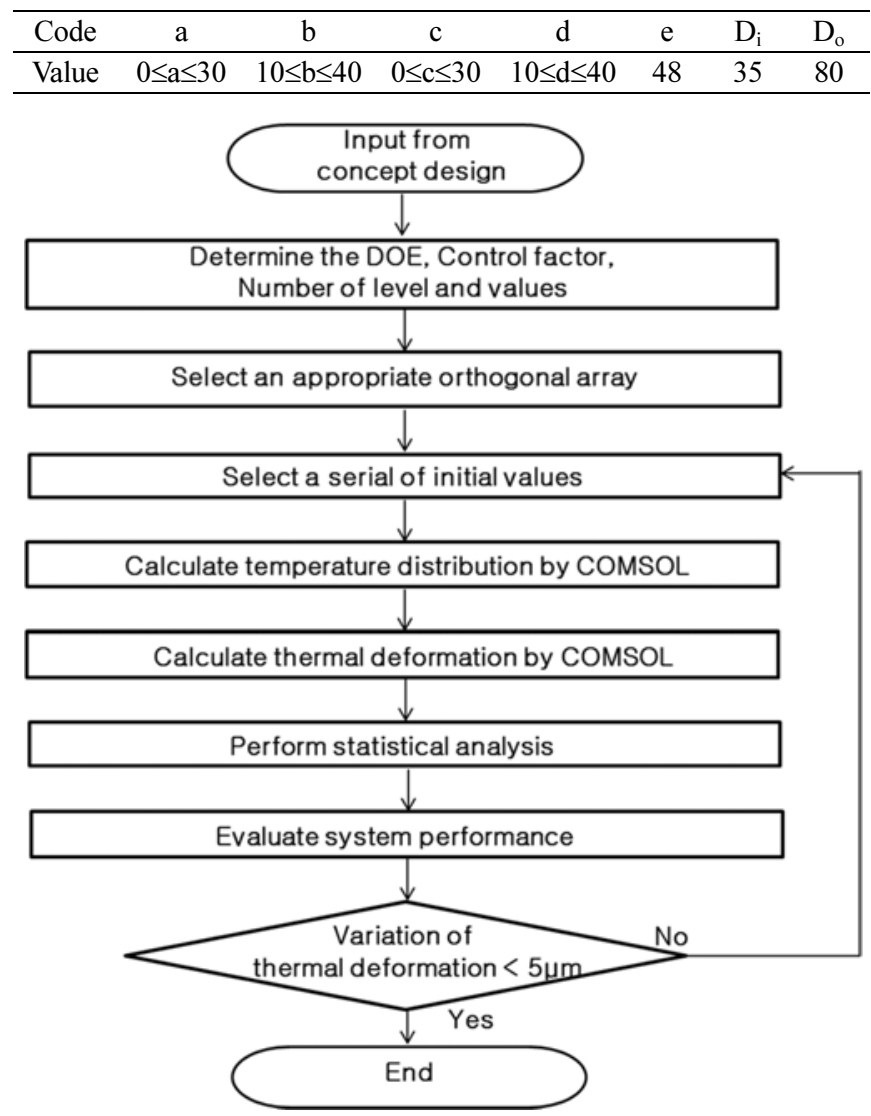

Fig. 10 Flowchart of the design of experiment process
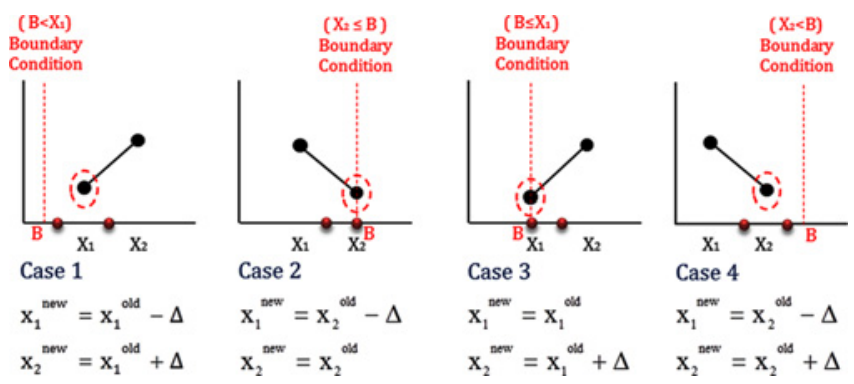

Fig. 11 Reset algorithm for tracing the optimal values 
The temperature distribution and the thermal deformation were simulated by heating at about $200^{\circ} \mathrm{C}$ with the optimal condition, and the variations of the temperature and the thermal deformation were estimated to be $2.9^{\circ} \mathrm{C}$ and $4.7 \mu \mathrm{m}$. In the case with the entire contact, the results were $8^{\circ} \mathrm{C}$ and $9.7 \mu \mathrm{m}$, respectively, as depicted in Figs. 12 and 13.

\section{Measurement and Evaluation}

To evaluate the proposed heating roll, the temperature and thermal deformation were measured as shown in Fig. 14. Five linear voltage differential transformers (LVDTs) of displacement sensors were

Table 4 Second orthogonal array and the simulation results

\begin{tabular}{ccccccc}
\hline Order & $\mathrm{a}$ & $\mathrm{b}$ & $\mathrm{c}$ & $\mathrm{d}$ & $\begin{array}{c}\text { Thermal } \\
\text { deformation }[\mu \mathrm{m}]\end{array}$ & $\begin{array}{c}\text { Temperature } \\
\text { distribution }\left[{ }^{\circ} \mathrm{C}\right]\end{array}$ \\
\hline 1 & 30 & 10 & 10 & 10 & 6.4 & 0.9 \\
\hline 2 & 30 & 30 & 0 & 30 & 8.4 & 3.9 \\
\hline 3 & 10 & 30 & 10 & 10 & 7.9 & 1 \\
\hline 4 & 30 & 10 & 10 & 30 & 8.1 & 2.9 \\
\hline 5 & 30 & 30 & 0 & 30 & 8.4 & 3.9 \\
\hline 6 & 30 & 30 & 10 & 10 & 8.1 & 3 \\
\hline 7 & 10 & 30 & 10 & 30 & 9.5 & 1.8 \\
\hline 8 & 10 & 10 & 10 & 30 & 7.9 & 0.8 \\
\hline 9 & 10 & 10 & 0 & 30 & 7.1 & 1.1 \\
\hline 10 & 30 & 10 & 0 & 10 & 6.1 & 0.9 \\
\hline 11 & 30 & 30 & 0 & 10 & 7.3 & 1.1 \\
\hline 12 & 10 & 10 & 0 & 10 & 4.7 & 2.9 \\
\hline
\end{tabular}

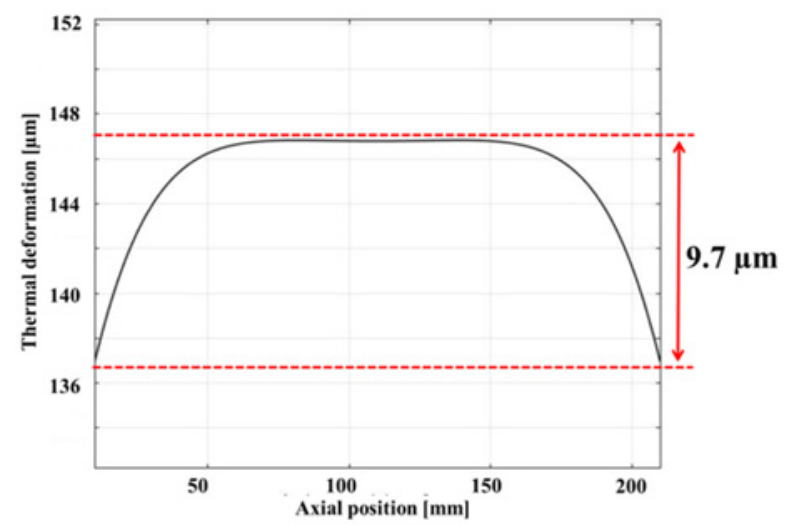

(a) Entire contact

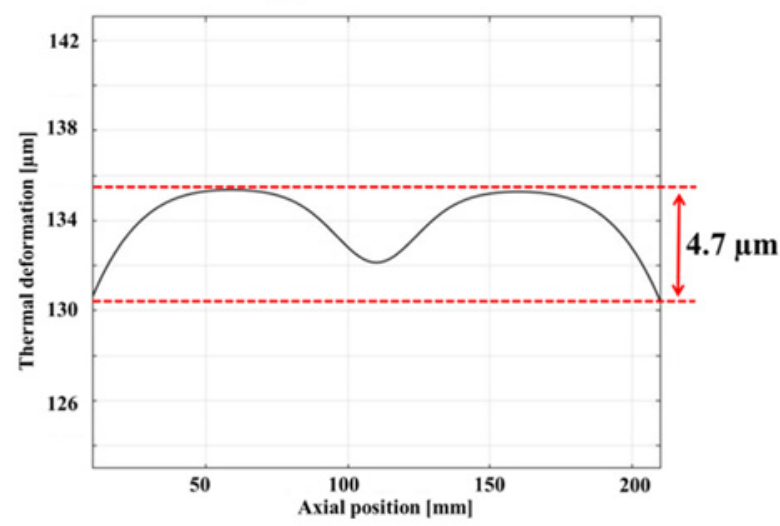

(b) Proposed model

Fig. 12 Comparison of the simulated thermal deformation installed on the moving stage, which was guided by a linear roller motion guide and pushed by an air cylinder. Then, the thermal deformation of the heating roll can be measured intermittently. The stage had repeatability of 1 micrometer. A black carbon tape (emissivity 0.95 ) was partially attached to the surface of the heating roll, and the temperature profile was measured by an infrared thermal camera. On the heating roll reaching a temperature steady state, the stage moved the measuring position forward from the stationary position a distance of $200 \mathrm{~mm}$, so that the probe touched the roll surface. For the purpose of minimizing the thermal radiation and heat conduction on the sensors, an insulating shield plate was covered and shortly opened for the 1-second measurement duration.

When the designed heating roll reached $200^{\circ} \mathrm{C}$, the variations of the temperature and the thermal deformation along the axial

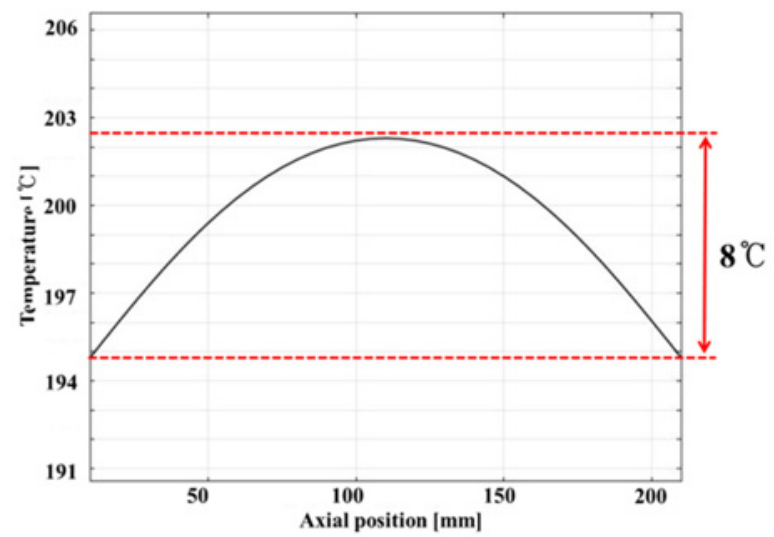

(a) Entire contact

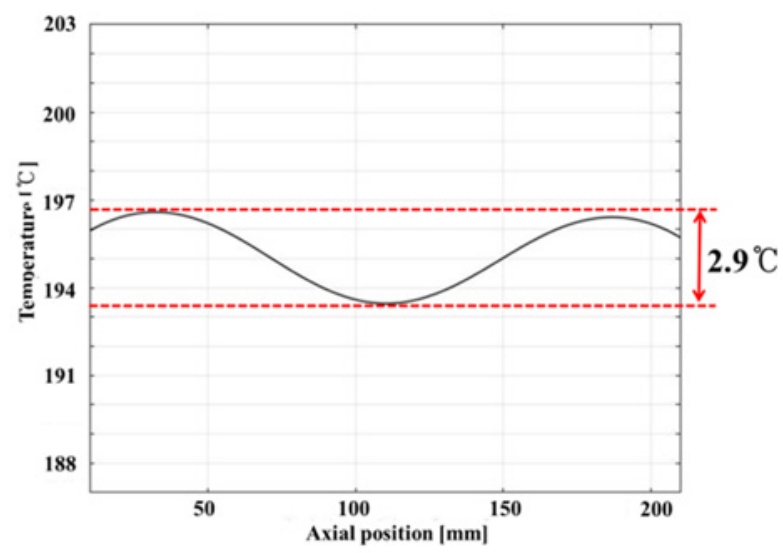

(b) Proposed model

Fig. 13 Comparison of the simulated temperature distribution

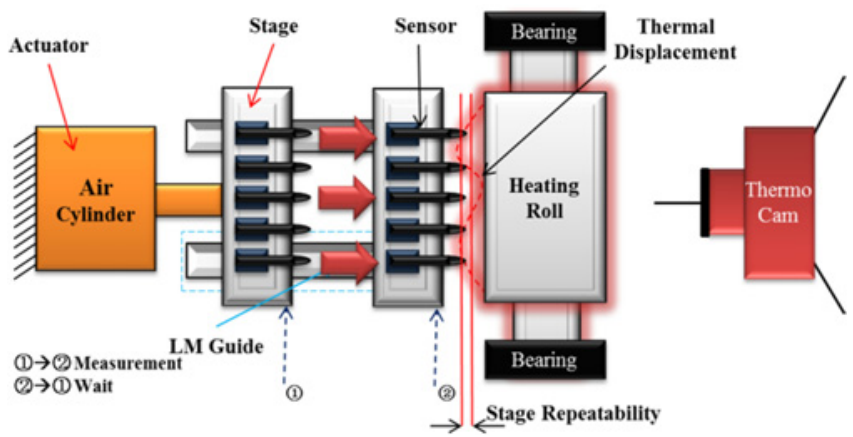

Fig. 14 Measurement setup for the thermal deformation 


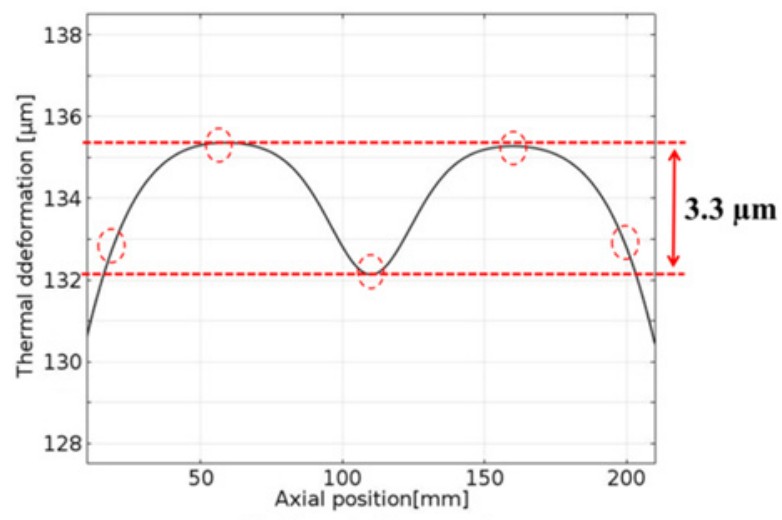

(a) Simulation result

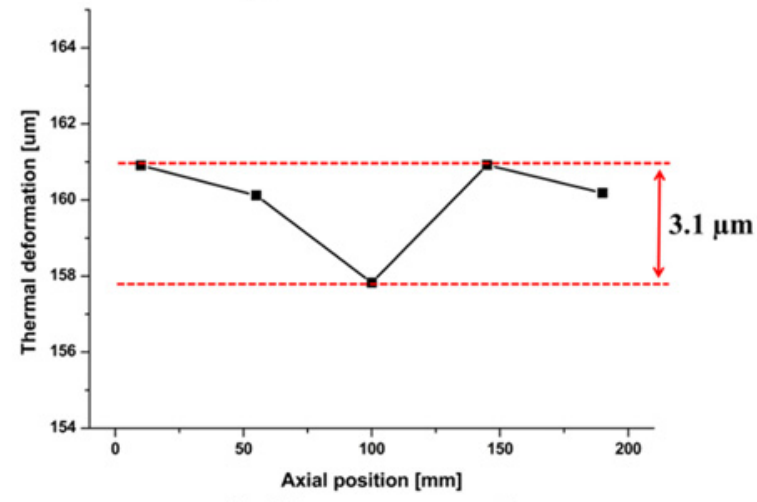

(b) Measurement result

Fig. 15 Comparison of the thermal deformation
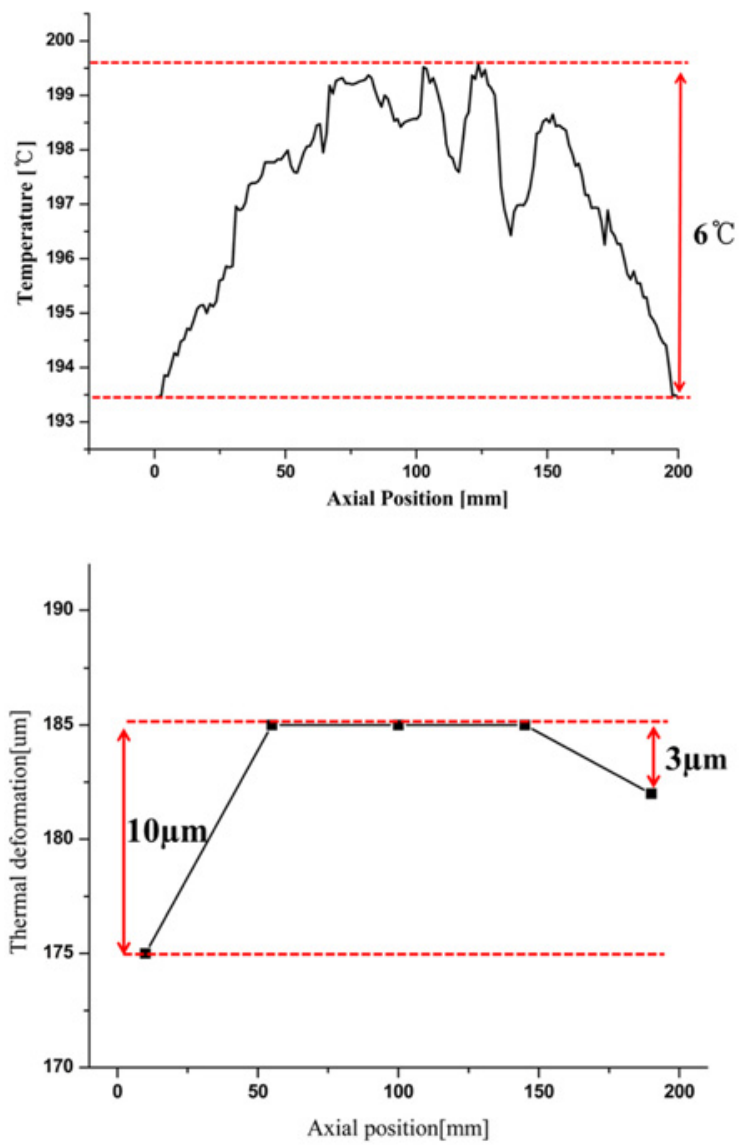

(a) Before optimization position were measured as $2.7^{\circ} \mathrm{C}$ and $3.1 \mu \mathrm{m}$, respectively, whereas the simulated results were $2.9^{\circ} \mathrm{C}$ and $3.3 \mu \mathrm{m}$, respectively. The comparisons indicated that the simulation model of the heating roll was well matched with the real one, as depicted in Figs. 13, 15 and 16.

Upon the validation of this design methodology, measurements of the heating roll were performed and compared before and after the optimization. The proposed design improved the uniformity of the temperature and the thermal deformation, from $6^{\circ} \mathrm{C}$ and $10 \mu \mathrm{m}$ (maximum) to $2.7^{\circ} \mathrm{C}$ and $3.1 \mu \mathrm{m}$, respectively, as depicted in Fig. 16 .

\section{Thermal Imprinting Results}

With the installation of the newly designed heating roll, the thermal imprint process was carried out. A roll-to-roll thermal imprinting machine was developed with a particular emphasis on the pressure uniformity, as shown in Fig. 17. The imprinting mold, made of electrolysis nickel plating with $50 \mu \mathrm{m}$ thickness and $200 \mathrm{~mm}$ by $200 \mathrm{~mm}$ imprinting area, was wound and clamped around the heating roll, in which 450 grid patterns with $20 \mu \mathrm{m}$ or $30 \mu \mathrm{m}$ of line width were engraved by photolithography. These were designed with consideration of the spreading resistance, line drop, contact resistance, and shadowing loss. A PET film was run between the heating roll and the impression roll as the heating roll was rotated by a motor. The impression roll was pushed against the heating roll by the air cylinder,
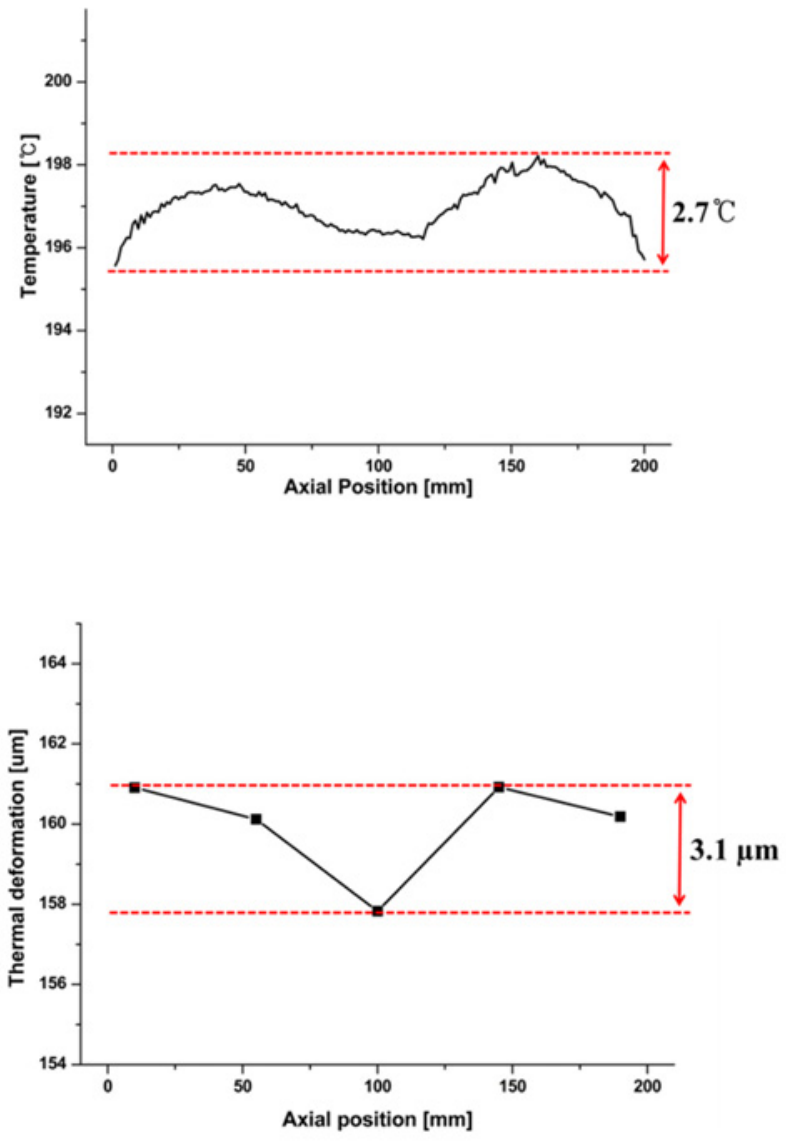

(b) After optimization

Fig. 16 Comparison of the uniformity of the temperature and the thermal deformation 
which was coupled through the ball joint as depicted in Fig. 17(b). The impressing force was monitored by the load cells that were attached on the housing wall of the impression roll. Table 5 indicates the experiment conditions of the R2R imprinting process. Fig. 18 depicts a schematic view of the imprinting mold and printed pattern and indicates the concerned width and thickness.

Fig. 19 shows a SEM image of the imprinted pattern and Fig. 20 shows the imprinted film, in which numbers are given along the width

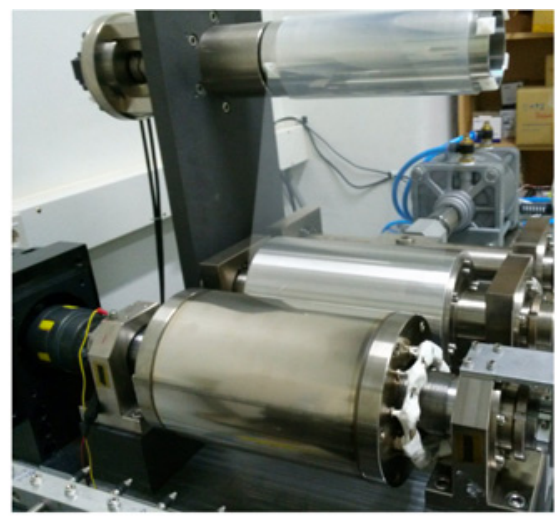

(a) Photo of the R2R thermal imprinting

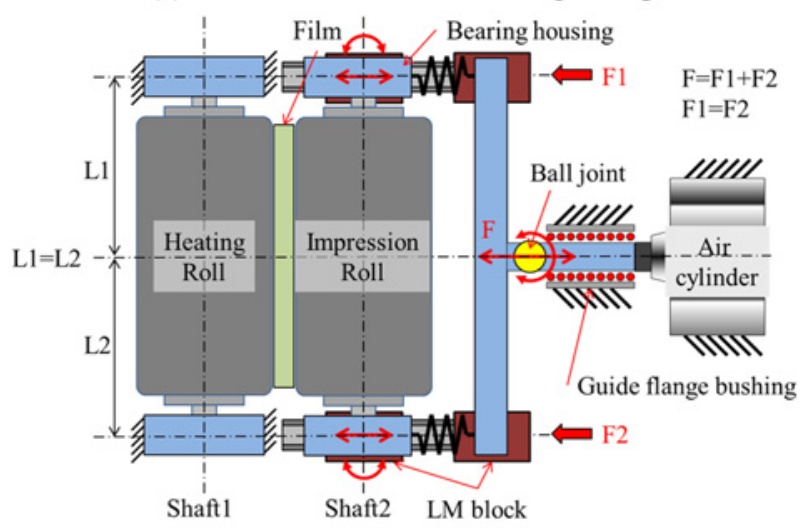

(b) Schematic of R2R thermal imprinting

Fig. 17 Experimental setup for roll-to-roll thermal imprinting

Table 5 Experiment conditions of the R2R imprinting process

\begin{tabular}{ccc}
\hline Parameter & Unit & Value \\
\hline Force & $\mathrm{kN}$ & $4.2,7.9,11,16$ \\
\hline \multirow{2}{*}{ Imprinting speed } & $\mathrm{RPM}$ & 6 \\
\cline { 2 - 3 } & $\mathrm{mm} / \mathrm{s}$ & 44 \\
\hline Roll temperature & ${ }^{\circ} \mathrm{C}$ & $105,155,200,240$ \\
\hline Room temperature & ${ }^{\circ} \mathrm{C}$ & 23 \\
\hline Pattern information & $\mu \mathrm{m}$ & $\begin{array}{c}20 \times 30 \text { (proto type) } \\
30 \times 30 \text { (optimized one) }\end{array}$ \\
\hline Imprinting area & $\mathrm{mm}$ & $200 \times 200$ \\
\hline
\end{tabular}
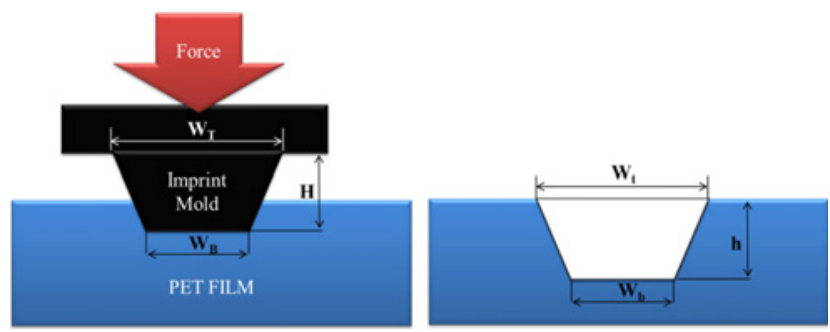

Fig. 18 Configuration of the imprinting mold and the printed pattern to be evaluated in terms of the uniformity. The measured values of the printed patterns are compared in Fig. 21, in which the patterned top line widths are uniformly fabricated over a printing area of $200 \mathrm{~mm}$ by $200 \mathrm{~mm}$. The deviation of top line is reduced from $11.9 \mu \mathrm{m}$ to $1.5 \mu \mathrm{m}$ and that of bottom line is reduced from $4.6 \mu \mathrm{m}$ to $2.1 \mu \mathrm{m}$ represented in Fig. 21. Moreover, the replication ratios, which were the portions of the mold pattern volume that were replicated to the film and were defined by Eq. (2), were compared between the prototype and proposed roll, as shown in Fig. 22. From these results, the replication rates of the proposed roll were distributed more uniformly than the prototype, although they indicated small values due to $16 \mathrm{kN}$ of applying load in the laboratory situation.

$$
R_{\text {replication }}=\frac{\text { Sectional area of the imprinted pattern }}{\text { Sectional area of the mold pattern }}=\frac{\left(W_{t}+W_{b}\right) \times h}{\left(W_{T}+W_{B}\right) \times H}
$$

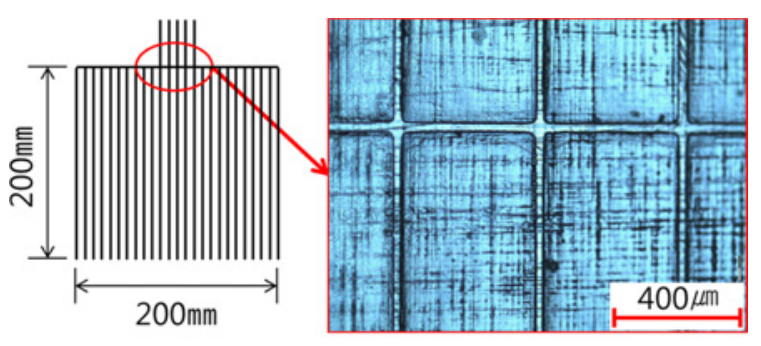

(a) Micro-Scope image of the imprinting mold with a constant width gridline structure

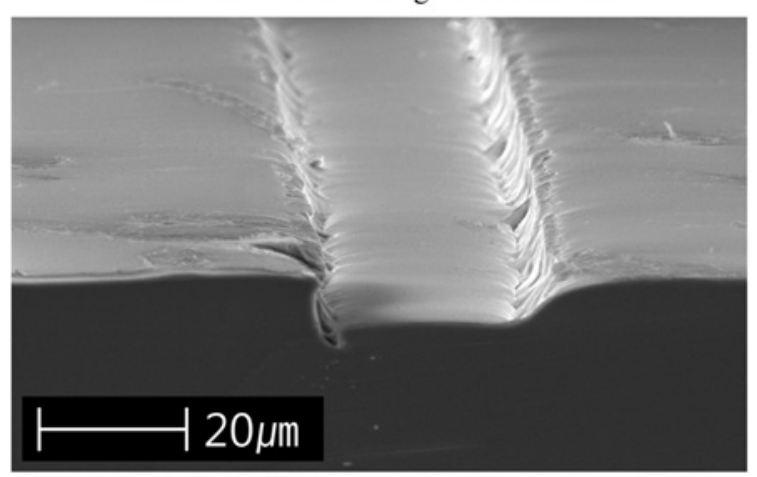

(b) SEM image of the imprinted pattern

Fig. 19 Measurement results of the imprinting mold and imprinted pattern

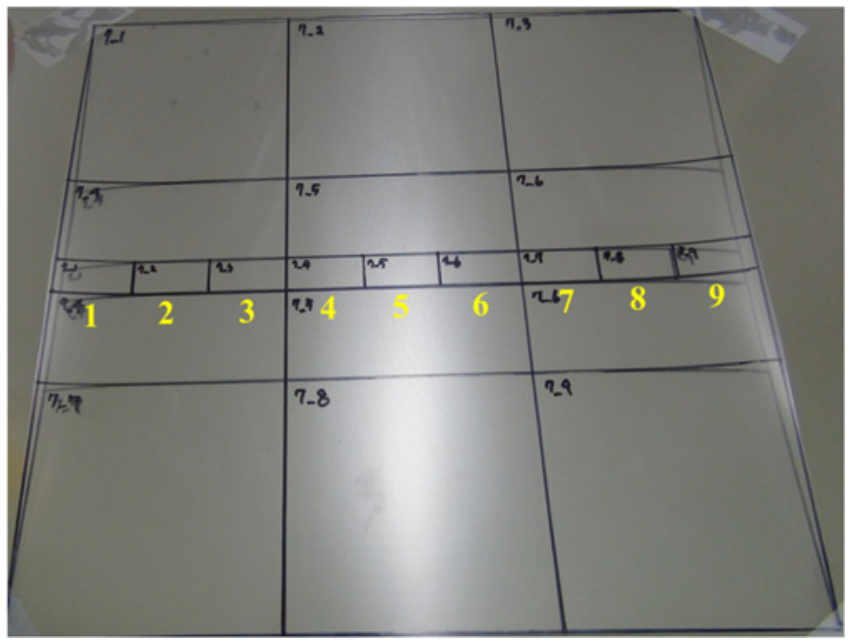

Fig. 20 Printed pattern by the R2R thermal imprinting process 


\section{Conclusions}

An imprinting setup for producing large area printing through the roll-to-roll thermal imprint was designed and manufactured with consideration of the pressure uniformity. First, the impressing load was applied symmetrically by the impressing roll. Second, the heating roll was manufactured by shrink fit assembly through the protrusions of the

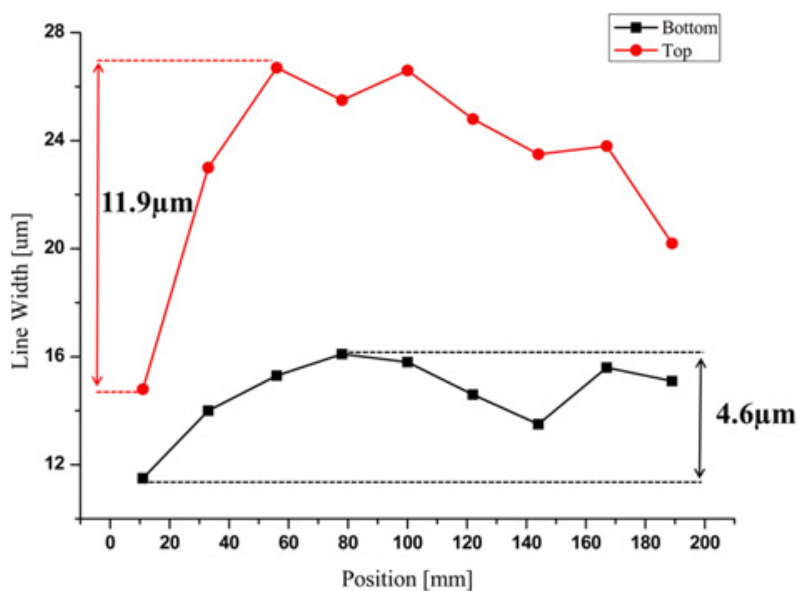

(a) Prototype

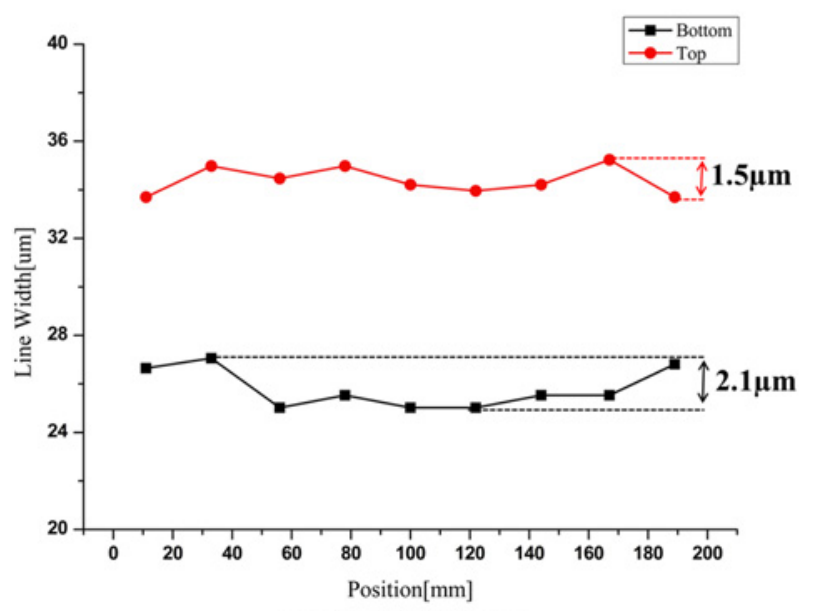

(b) Proposed model

Fig. 21 Patterned line width according to the roll position

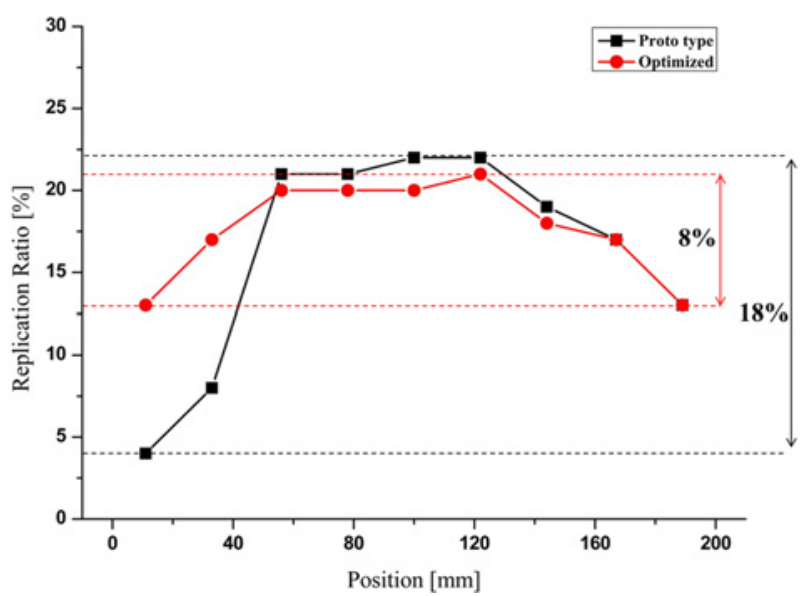

Fig. 22 Comparison of the replication rate between the prototype and the proposed one shaft. The protrusions were designed to improve the uniformity of the temperature distribution, which resulted in the uniform thermal deformation of the heating roll. Simulations of both temperature and thermal deformation associated with the optimization, adopting D.O.E, were conducted. The heating roll was manufactured and evaluated with the optimized condition.

The measured results showed that the simulation agreed well with the manufactured one, and the uniformity of the thermal deformation of the heating roll was improved from $9.7 \mathrm{~mm}$ to $4.7 \mathrm{~mm}$ by simulation results along a printed area of $200 \mathrm{~mm}$ by $200 \mathrm{~mm}$, while the uniformity of temperature distribution was improved from $8 \mathrm{~K}$ to $2.9 \mathrm{~K}$. Results only have $0.2 \mathrm{~mm}$ difference between simulation and measurement. They are pretty close together. The imprinting was performed to evaluate the performance of the improved heating roll and compared with that of prototype. The printing results showed that the replication ratio of printed patterns was improved significantly, from $18 \%$ of variance to $8 \%$ along the distance of the roll length.

\section{ACKNOWLEDGEMENT}

This work was supported by a National Research Foundation of Korea (NRF) grant funded by the Korean government (MSIP) (No. NRF-2013R1A2A1A05006329), Basic Science Research Program through the National Research Foundation of Korea (NRF) funded by the Ministry of Education (No. NRF-2012R1A1A2044089) and Technology Innovation Program (10053248, Development of Manufacturing System for CFRP (Carbon Fiber Reinforced Plastics) Machining) partly supported by the Ministry of Trade, industry \& Energy(MOTIE, Korea).

\section{REFERENCES}

1. Chou, S. Y., Krauss, P. R., and Renstrom, P. J., "Nanoimprint Lithography," Journal of Vacuum Science \& Technology B, Vol. 14, No. 6, pp. 4129-4133, 1996.

2. Yu, J.-S., Kim, I., Kim, J.-S., Jo, J., Larsen-Olsen, T. T., et al., "Silver Front Electrode Grids for ITO-Free All Printed Polymer Solar Cells with Embedded and Raised Topographies, Prepared by Thermal Imprint, Flexographic and Inkjet Roll-to-Roll Processes," Nanoscale, Vol. 4, No. 19, pp. 6032-6040, 2012.

3. Lee, S.-C., Kim, C.-K., Song, H.-E., and Kim, Y.-S., "Finite Element Analysis of Crystalline Silicon Solar Cell in Screen Printing Process by Using Taguchi Method,” Int. J. Precis. Eng. Manuf., Vol. 14, No. 4, pp. 635-642, 2013.

4. Jeong, T.-G., Seo, Y.-H., Kim, S., Song, J., Ko, S.-L., et al., "Roll to Roll Air-Floating Oven Drying Process Design and Analysis for Printed Electronics,” Int. J. Precis. Eng. Manuf., Vol. 15, No. 7, pp. 1303-1310, 2014.

5. Kim, J. Y., Choi, H.-J., and Woo, C.-S., "Nanoscale Thin Film Transfer Using Elastomer-Covered Roll with Buffer Cavities,” Int. J. Precis. Eng. Manuf., Vol. 15, No. 4, pp. 711-716, 2014. 
6. Kang, H. and Baumann, R. R., "Mathematical Modeling and Simulations for Machine Directional Register in Hybrid Roll-to-Roll Printing Systems,” Int. J. Precis. Eng. Manuf., Vol. 15, No. 10, pp. 2109-2116, 2014.

7. Haisma, J. Verheijen, M., Heuvel, K. V. D., and Berg, J. V. D., "Moldassisted Nanolithography: A Process for Reliable Pattern Replication," Journal of Vacuum Science and Technology B., Vol. 14, No. 6, pp. 4124-4128, 1996.

8. Bender, M., Otto, M., Hadam, B., Vratzov, B., Spangenberg, B., et al., "Fabrication of Nanostructures Using a UV-Based Imprint Technique," Microelectronic Engineering, Vol. 53, No. 1, pp. $233-$ 236,2000

9. Ahn, S., Cha, J., Myung, H., Kim, S.-M., and Kang, S., "Continuous Ultraviolet Roll Nanoimprinting Process for Replicating Large-Scale Nano-and Micropatterns," Applied Physics Letters, Vol. 89, No. 21, pp. 213101, 2006.

10. Yeo, L. P., Ng, S. H., Wang, Z., Wang, Z., and De Rooij, N. F., "Micro-Fabrication of Polymeric Devices Using Hot Roller Embossing," Microelectronic Engineering, Vol. 86, No. 4, pp. 933936, 2009.

11. Lan, S., Song, J.-H., Lee, M. G., Ni, J., Lee, N. K., et al., "Continuous Roll-to-Flat Thermal Imprinting Process for LargeArea Micro-Pattern Replication on Polymer Substrate," Microelectronic Engineering, Vol. 87, No. 12, pp. 2596-2601, 2010.

12. Kettle, J., Rees, A., Brousseau, E., and Horie, M., "LowTemperature Thermal Nanoimprint Lithography of Anti-Reflective Structures for Flexible Low Band Gap Organic Solar Cells,” Journal of Physics D: Applied Physics, Vol. 46, No. 10, Paper No. 105102, 2013.

13. Tseng, A., Tong, S., and Chen, T., "Thermal Expansion and Crown Evaluations in Rolling Processes," Materials \& Design, Vol. 18, No. 1, pp. 29-41, 1997.

14. Guo, Z.-F., Li, C.-S., Xu, J.-Z., Liu, X.-H., and Wang, G.-D., "Analysis of Temperature Field and Thermal Crown of Roll during Hot Rolling by Simplified FEM," Journal of Iron and Steel Research, International, Vol. 13, No. 6, pp. 27-48, 2006.

15. Abbaspour, M. and Saboonchi, A., "Work Roll Thermal Expansion Control in Hot Strip Mill," Applied Mathematical Modelling, Vol. 32, No. 12, pp. 2652-2669, 2008.

16. Yun, D., Son, Y., Kyung, J., Park, H., Park, C., et al., "Development of Roll-to-Roll Hot Embossing System with Induction Heater for Micro Fabrication," Review of Scientific Instruments, Vol. 83, No. 1, Paper No. 015108, 2012.

17. Cheknane, A., "Optimal Design of Electrode Grids Dimensions for ITO-Free Organic Photovoltaic Devices," Progress in Photovoltaics: Research and Applications, Vol. 19, No. 2, pp. 155-159, 2011.

18. Shabana, M. M., Saleh, M. B., and Soliman, M. M., "Optimization of Grid Design for Solar Cells at Different Illumination Levels," Solar Cells, Vol. 26, No. 3, pp. 177-187, 1989.
19. Budynas, R. G. and Nisbett, K., "Shigley's Mechanical Engineering Design,” McGraw-Hill, $9^{\text {th }}$ Ed., pp. 398-399, 2009.

20. Yoshida, Y., "Research on Thermal Deformation of a Vertical Milling Machine," Technical Report of Mechanical Engineering Laboratory, No. 82, 1975.

21. Jedrzejewski, J., "Effect of the Thermal Contact Resistance on Thermal Behaviour of the Spindle Radial Bearings," International Journal of Machine Tools \& Manufacture, Vol. 28, No. 4, pp. 409416, 1988

22. Jedrzejewski, J. and Moddrzycki, W., "A New Approach to Modelling Thermal Behaviour of a Machine Tool under Service Conditions," CIRP Annals-Manufacturing Technology, Vol. 41, No. 1, pp. 455-458, 1992.

23. Kim, S.-M. and Lee, S.-K., "Thermally-Induced Mechanical Behavior of the Press-Fitted Cylindrical Structure," J. Korean Soc. Precis. Eng., Vol. 15, No. 7, pp. 139-148, 1998.

24. Bajracharya, I., Ito, Y., Nakayama, W., Moon, B.-J., and Lee, S.-K., "Characterization of Thermal Contact Resistance Doped with Thermal Interface Material,” J. Korean Soc. Precis. Eng., Vol. 30, No. 9, pp. 943-950, 2013. 